\title{
Vertical Aluminophosphate Molecular Sieve Crystals Grown at Inorganic-Organic Interfaces
}

\author{
Sue Feng and Thomas Bein*
}

Tubular aluminophosphate molecular sieve crystals were grown at an organic interface with their channels ( 7 angstroms in cross section) vertical to the substrate. To induce surface nucleation and oriented growth of $\mathrm{AlPO}_{4}-5$ crystals, organophosphonate layers cross-linked with $\mathrm{Zr}(\mathrm{IV})$ were assembled on a gold substrate and the modified substrate was immersed in a hydrothermal bath containing reagents for the synthesis of the molecular sieve. Reflection-absorption infrared studies demonstrated the stability of the phosphonate layers under these conditions. Drastic changes in the morphology of the surface-grown crystals from spherical agglomerates to vertical needles to thin tilted needles could be achieved by adjusting the water content of the synthesis bath. Nitrogen sorption in these structures on a piezoelectric device confirmed the presence of zeolitic microporosity.

Supramolecular preorganization and templating are powerful principles for controlled crystal growth (1). Our previous example of oriented zeolite crystal films has demonstrated the great utility of organophosphonate films for inducing nucleation and growth of oriented molecular sieves (2). In that case, fragile cubic zincophosphate crystals were prepared at low temperature. We have now discovered that it is possible to grow oriented, stable aluminophosphate crystals with vertical channels on zirconium phosphonate $(\mathrm{ZrP})$ layers on a gold substrate. Oriented nanometer-sized channel structures are of substantial interest for sizeselective chemical sensors, separation membranes, and optical systems. Zeolite molecular sieves (3) can selectively sorb molecules on the basis of their size, shape, polarity, and acid-base properties. The pore structure of $\mathrm{AlPO}_{4}-5$ is essentially a hexagonal array of parallel cylinders of uniform cross section $(7 \AA)$. In addition, $\mathrm{AlPO}_{4}-5$ exhibits excellent thermal stability (4). A number of zeolite films and membranes have been prepared, for example, through the deposition of growing crystals on metalmetal-oxide supports (5-11). Films of laterally oriented crystals of the silicalite- 1 type were grown from continuous silica gel precursor layers on silicon (6). Aluminophosphate crystals embedded in a polymer film have been aligned in electric fields (12).

We were able to form a self-assembled oriented $\mathrm{ZrP}$ trilayer on gold substrates (silicon wafers with a $2000 \AA$ gold layer on a $100 \AA$ chromium layer, precleaned with air plasma) by first adsorbing a monolayer from a $1.0 \mathrm{mM}$ solution of 11-mercapto-1-undecanol (MUD) in ethanol for 48 hours and then phosphorylating the layer with a mixture of $0.2 \mathrm{M} \mathrm{POCl}_{3}$ and $0.2 \mathrm{M} \mathrm{2,4,6-}$

Department of Chemistry, Purdue University, West Lafayette, IN 47907, USA.

*To whom correspondence should be addressed. collidine to give the corresponding phosphate (MUP) $(13,14)$. The substrates were sequentially immersed in $5.0 \mathrm{mM}$ zirconyl chloride and $1.25 \mathrm{mM} \mathrm{1,10-decanediylbis-}$ phosphonic acid (DBPA) aqueous solutions at room temperature to give the desired $\mathrm{ZrP}$ trilayer films.

The typical conditions for the synthesis of aluminophosphate molecular sieves span a temperature range of $120^{\circ}$ to $200^{\circ} \mathrm{C}$ at a pH of $3.0 \pm 0.5$. These are highly corrosive conditions for most self-assembled organic layers. We have therefore studied the thermal stability of the $\mathrm{ZrP}$ films before crystallization experiments were carried out. In the reflectionabsorption infrared (RAIR) spectra of these films, the asymmetric and symmetric $\mathrm{CH}_{2}$ stretching bands for the $\mathrm{ZrP}$ trilayer at 2926 and $2853 \mathrm{~cm}^{-1}$ retained their intensity after heating at $150^{\circ} \mathrm{C}$ at a pH of 3.0 for 24 hours. The mid-infrared region of the spectrum of a $\mathrm{ZrP}$ trilayer at $1077 \mathrm{~cm}^{-1}$ [asymmetric phosphonate stretch, $\left.\nu_{\mathrm{a}}\left(\mathrm{PO}_{3}{ }^{2-}\right)\right]$ was also unchanged. These findings indicate that $\mathrm{ZrP}$ films are thermally stable at $150^{\circ} \mathrm{C}$ and acidic $\mathrm{pH}$. Even at $180^{\circ} \mathrm{C}$ and a $\mathrm{pH}$ of 3 , the $\mathrm{ZrP}$ films were stable for at least 12 hours as determined by RAIR. The thermal stability of these $\mathrm{ZrP}$ films is related to the high stability of their solid analogs with strong bonding in phosphonate-Zr(IV) networks (15-17).

In view of the potential applications mentioned above, it was of interest to control the surface-crystal growth such that a vertical channel system results. Wilson and co-workers synthesized $\mathrm{AlPO}_{4}-5$ molecular sieves with spherical morphology when prepared at $150^{\circ} \mathrm{C}$ and a crystallization time of 4 to 24 hours (18). Other syntheses of the $\mathrm{AlPO}_{4}-5$ system (several days at about $190^{\circ} \mathrm{C}$ ) resulted in hexagonal prisms up to $900 \mu \mathrm{m}$ long $(19,20)$.

We have combined several of the above synthesis methods for the surface growth of large hexagonal crystals. The $\mathrm{AlPO}_{4}-5$ crystals were synthesized hydrothermally in poly- tetrafluoroethylene-lined autoclaves without stirring under autogenous pressure at $180^{\circ} \mathrm{C}$ from boehmite (AlOOH), 85\% orthophosphoric acid, 1,4 diazabicyclo[2.2.2]octane (DABCO), and distilled water. The molar water content $d=\left[\mathrm{H}_{2} \mathrm{O}\right] /\left[\mathrm{Al}_{2} \mathrm{O}_{3}\right]$ was adjusted from 60 to 600 . The $\mathrm{pH}$ of the mixture was $3.5 \pm 0.2$. For crystal growth on the surface, the $\mathrm{ZrP}$-modified gold substrates were placed face down into the gel. After 8 to 12 hours of reaction, the samples were washed with water and dried at $180^{\circ} \mathrm{C}$ for 1 hour.

The $\mathrm{ZrP}$ trilayer films induce the surface growth from the hydrothermal synthesis baths of aluminophosphate crystals with striking morphologies (Figs. 1 and 2). No zeolite crystals attach to unmodified gold surfaces. The scanning electron microscopy (SEM) images show that $\mathrm{AlPO}_{4}-5$ crystals grow with their $c$ axes oriented perpendicular to the gold surfaces. The micrographs also show that changing the water concentrations in the hydrothermal synthesis has a profound effect on the orientation, morphology, and aspect ratios of the surfaceattached crystals (Table 1) (see below).

The films obtained in all of our experiments exhibited $x$-ray diffraction (XRD) patterns corresponding to that of the AFI structure, that is, $\mathrm{AlPO}_{4}-5$. Grazing-angle incidence $\left(1.5^{\circ}\right) \mathrm{XRD}$ patterns of the surface-grown $\mathrm{AlPO}_{4}-5$ crystals (Fig. 3) show a strongly enhanced intensity of the (002) peak at a Bragg angle $2 \theta$ of $21.3^{\circ}$. This enhanced intensity confirms the preferred
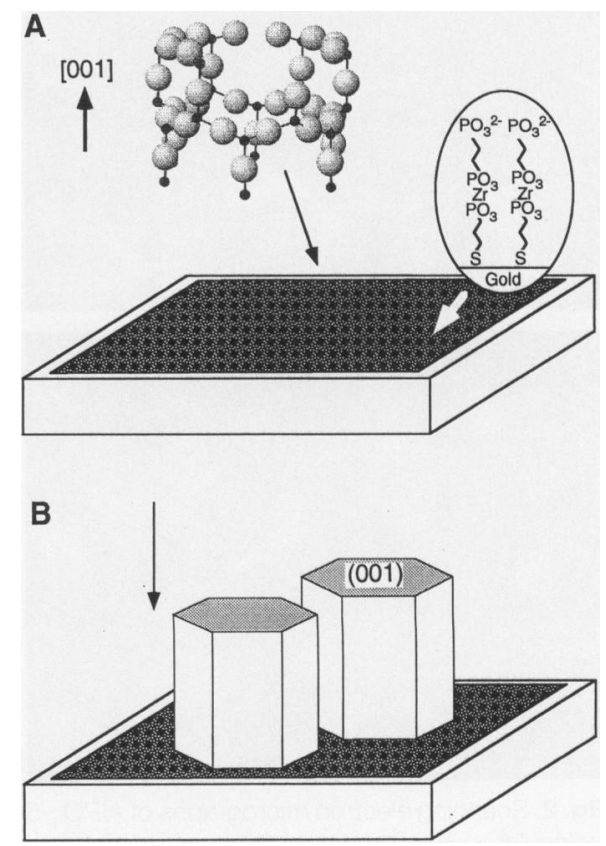

Fig. 1. Proposed reaction scheme for the growth of aluminophosphate molecular sieves on organophosphonate films: (A) aluminophosphate nuclei attach on organophosphonate film; (B) growth of hexagonal crystals. 
vertical $c$-axis orientation of the hexagonal crystals. The crystals are very strongly bonded to the substrate and can survive hours of sonication.

Several parameters have a strong impact on the growth of $\mathrm{AlPO}_{4}-5$ crystals on the modified gold surface. Only the MUP-ZrDBPA trilayers promoted significant crystal growth; no crystals were grown on gold modified with only MUP $\left[-\mathrm{S}\left(\mathrm{CH}_{2}\right)_{11}-\mathrm{O}-\mathrm{PO}_{3} \mathrm{H}_{2}\right]$ or MUP-Zr. We relate the absence of crystal growth on the $\mathrm{Au}-\mathrm{S}\left(\mathrm{CH}_{2}\right)_{11}-\mathrm{O}-\mathrm{PO}_{3} \mathrm{H}_{2}$ monolayer to its poor thermal stability at acidic $\mathrm{pH}$. The RAIR spectrum shows that MUP monolayers are not stable at $180^{\circ} \mathrm{C}$ for longer than 2 hours. When the added zirconyl layer was presented to the $\mathrm{AlPO}_{4}-5$ synthesis bath, no crystal growth was observed either, suggesting a lack of electrostatic interactions. The templating agent DABCO also plays an important role. When it was substituted with tripropylamine, no $\mathrm{AlPO}_{4}-5$ growth occurred even though the bulk synthesis proceeded without difficulty. This effect could be related to the dipositive charge on protonated $\mathrm{DABCO}$ and associated surface interactions.

We were also interested in the nature of the strong interactions between the aluminophosphate nuclei and the phosphonate surface. We performed quenching reactions under bulk synthesis conditions to explore the
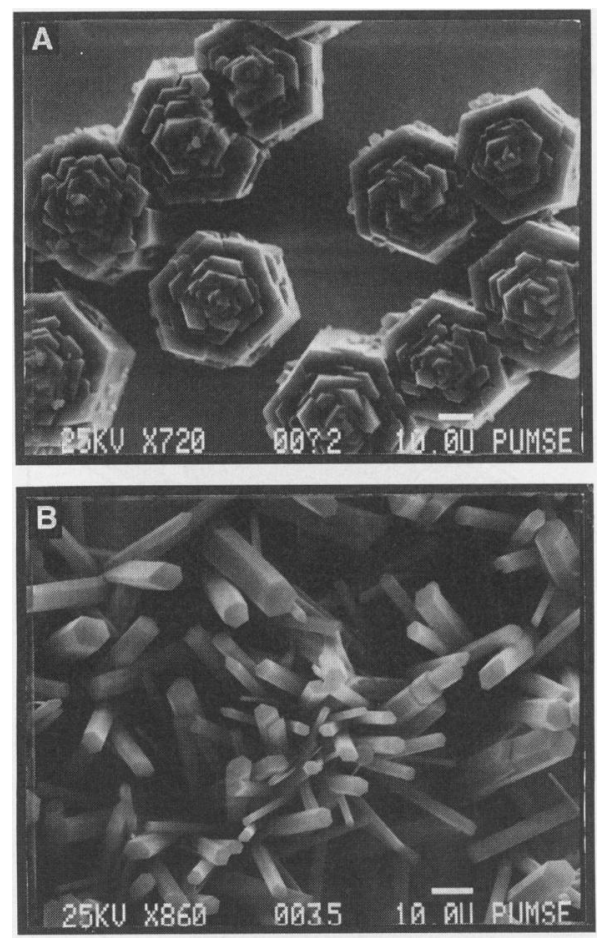

Fig. 2. Scanning electron micrographs of $\mathrm{AlPO}_{4}-5$ molecular sieves grown in 8 hours on organophosphonate film assembled on a modified gold substrate $($ bar $=10 \mu \mathrm{m})$. (A) Water content in synthesis bath $d=\left[\mathrm{H}_{2} \mathrm{O}\right] /\left[\mathrm{Al}_{2} \mathrm{O}_{3}\right]=300$, synthesis temperature $T_{\mathrm{s}}=180^{\circ} \mathrm{C}$; $(\mathrm{B}) d=600, T_{\mathrm{s}}=$ $180^{\circ} \mathrm{C}$. association between the phophonate surface and zeolite crystal faces. Ethylphosphonic acid $\left(\mathrm{H}_{2} \mathrm{PO}_{3} \mathrm{CH}_{2} \mathrm{CH}_{3}\right)(25 \mathrm{mmol})$ was added to the bulk $\mathrm{AlPO}_{4}-5$ crystallization mixture after $40 \mathrm{~min}$, and the resulting suspension was placed back into the oven at $180^{\circ} \mathrm{C}$ for another 8 hours. The SEM and XRD data show that addition of the "quenching agent" blocks further crystal growth. The size and morphology of quenched crystals are similar to those from a regular synthesis stopped after $40 \mathrm{~min}$. These results suggest that the phosphonic acid groups have a strong affinity to the growing faces of the $\mathrm{AlPO}_{4}-5$ crystals. The $\{001\}$ faces appear to interact most effectively with the phosphonate surface, thus favoring the vertical orientation of the $c$ axes.

We found that the morphology and size of surface-grown $\mathrm{AlPO}_{4}-5$ crystals can be controlled by varying the temperature and the water content of the synthesis bath. We obtained semispherical aggregates at $150^{\circ} \mathrm{C}$ and lower water content $(d=60)$. Dilution of the system produces larger hexagonal prismatic

Table 1. Effect of the water concentration $d=$ $\left[\mathrm{H}_{2} \mathrm{O}\right] /\left[\mathrm{Al}_{2} \mathrm{O}_{3}\right]$ on the morphology of surface-attached $\mathrm{AlPO}_{4}-5$ crystals. We prepared gels with molar composition $1.0 \mathrm{Al}_{2} \mathrm{O}_{3}, 1.0 \mathrm{P}_{2} \mathrm{O}_{5}, 3.2$ DABCO, $d \mathrm{H}_{2} \mathrm{O}$ by first adding boehmite to $\mathrm{H}_{3} \mathrm{PO}_{4}-\mathrm{H}_{2} \mathrm{O}$, stirring for 8 hours, adding DABCO, and stirring for 12 more hours at $25^{\circ} \mathrm{C}$, followed by hydrothermal treatment.

\begin{tabular}{|c|c|c|c|}
\hline \multirow{2}{*}{$\begin{array}{l}\mathrm{H}_{2} \mathrm{O} \\
\text { content } \\
\text { (d) }\end{array}$} & \multicolumn{3}{|c|}{ Crystal } \\
\hline & $\begin{array}{c}\text { Length } \\
(\mu \mathrm{m})\end{array}$ & $\begin{array}{l}\text { Width } \\
(\mu \mathrm{m})\end{array}$ & Orientation \\
\hline 300 & $30-50$ & $40-50$ & Vertical \\
\hline 400 & $20-30$ & $3-6$ & Tilted \\
\hline 600 & $30-50$ & $2-10$ & Tilted \\
\hline
\end{tabular}

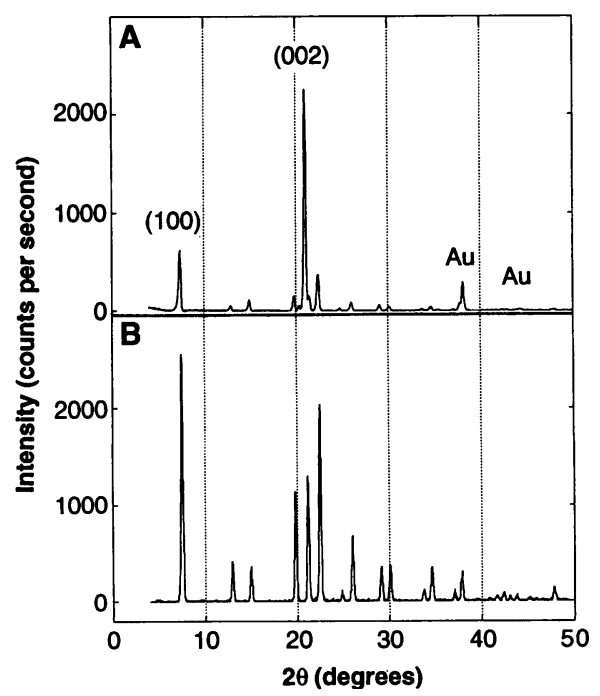

Fig. 3. X-ray diffraction patterns of (A) $\mathrm{AlPO}_{4}-5$ molecular sieve film on organophosphonate film (d $=300, T_{\mathrm{s}}=180^{\circ} \mathrm{C}$ ) and of (B) bulk AlPO $_{4}-5$ molecular sieve synthesized under similar conditions. crystals, with increasing aspect ratio relative to the $c$ axis (Fig. 2). When $d=300$, close to $100 \%$ of the hexagonal crystals are almost perfectly aligned with their $c$ axis perpendicular to the surface. When $d=400$ and 600 , a majority of the crystals grow with their $c$ axes in an oriented upright fashion, but the crystals are tilted.

To probe the porosity of the surfacegrown hexagonal channel systems, we grew them on the gold electrodes of a quartz crystal microbalance (11). We removed the organic templating agent by heating under oxygen at $350^{\circ} \mathrm{C}$ for 8 hours. Thermogravimetric analysis indicated that close to $98 \%$ of the organic templates was removed under these conditions. Microscopy showed that the crystals maintain their orientation after calcination. The nitrogen adsorption isotherm shows the typical type I shape with a significant uptake at low partial pressures which confirms the zeolitic microporosity the surface-grown crystals (Fig. 4). This ex:periment also demonstrates the high stabit ity of the channel systems, which is importance for future applications.

Our results demonstrate that it is possE్ ble to grow stable, vertically oriented ones dimensional $\mathrm{AlPO}_{4}-5$ crystals on zirconum. phosphonate-modified gold surfaces. As bulk-quenching reactions, the phosphonate surfaces strongly interact with the growing $\mathrm{AlPO}_{4}-5$ crystals. This interaction can adjusted such that the hexagonal $\{001\}$ faces grow parallel to the substrate, leading channel systems with their $c$ axes oriente normal to the surface. Because it seems less likely that individual ions could assemb-6 such an oriented structure without epitax control, we propose that small, ring-shaped subunits assemble on the substrate (Fig. $1 \%$ The oriented $\mathrm{AlPO}_{4}-5$ structures could

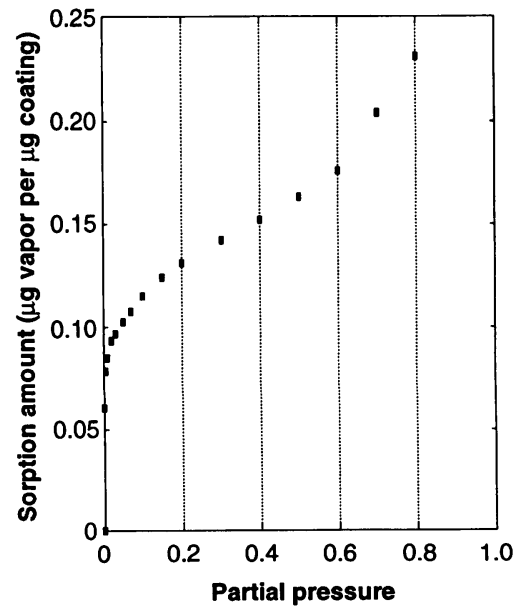

Fig. 4. Nitrogen sorption isotherm of $\mathrm{AlPO}_{4}-5$ crystals grown on the surface of a quartz crystal microbalance $\left(d=300\right.$ and $\left.T_{\mathrm{s}}=180^{\circ} \mathrm{C}\right)$ at $-196^{\circ} \mathrm{C}$ (partial pressure $P / P_{0}$, where $P_{0}=760$ torr). 
used in such applications as catalytic membranes with true molecular selectivity or in the controlled access of molecules of preselected size to a sensor surface.

\section{REFERENCES AND NOTES}

1. S. Mann, Nature 365, 499 (1993); S. Mann et al., Science 261, 1286 (1993); S. Mann et al., Mater. Res. Soc. Bull. 17, 32 (1992).

2. S. Feng and T. Bein, Nature 368, 834 (1994).

3. D. W. Breck, Zeolite Molecular Sieves (Krieger, Malabar, FL, 1984); R. M. Barrer, Hydrothermal Chemis try of Zeolites (Academic Press, New York, 1982); H. van Bekkum, E. M. Flanigen, J. C. Jansen, Eds. Introduction to Zeolite Science and Practice, vol. 58 of Studies in Surface Science and Catalysis (Elsevier New York, 1991); M. E. Davis, Acc. Chem. Res. 26 111 (1993); — and R. L. Lobo, Chem. Mater. 4 756 (1992); W. M. Meier and D. H. Olson, Atlas of Zeolite Structure Types (Butterworth-Heinemann, London, ed. 3, 1992).

4. J. M. Bennett, J. P. Cohne, E. M. Flanigen, J. J. Pluth, J. V. Smith, Am. Chem. Soc. Symp. Ser. 218, 109 (1983).

5. G. J. Myatt, P. M. Budd, C. Price, S. W. Carr, J. Mater. Chem. 2, 1103 (1992); M. W. Anderson, K. S. Pachis, J. Shi, S. W. Carr, ibid., p. 255.

6. J. C. Jansen and G. M. van Rosmalen, J. Cryst. Growth 128, 1150 (1993); J. H. Koegler et al., in Zeolites and Related Microporous Materials: State of the Art 1994, J. Weitkamp et al., Eds. vol. 84 of Studies in Surface Science and Cata
Iysis (Elsevier, New York, 1994), p. 307.

7. S. P. Davis, E. V. R. Borgstedt, S. L. Suib, Chem. Mater. 2, 712 (1990); K. E. Creasy et al., Mater. Res. Soc. Symp. Proc. 233, 157 (1991).

8. J. G. Tsikoyiannis and W. O. Haag, Zeolites 12, 126 (1992).

9. E. R. Geus, M. J. Den Exter, H. Van Bekkum, J. Chem. Soc. Faraday Trans. 88, 3101 (1992)

10. T. Bein, K. Brown, G. C. Frye, C. J. Brinker, J. Am. Chem. Soc. 111, 7640 (1989).

11. Y. Yan and T. Bein, J. Phys. Chem. 96, 9387 (1992).

12. J. Caro et al., Adv. Mater. 4, 273 (1992).

13. T. M. Putvinski et al., Langmuir 6, 1567 (1990)

14. B. L. Frey, D. G. Hanken, R. M. Corn, ibid. 9, 1815 (1993).

15. H. Lee, L. J. Kepley, H.-G. Hong, S. Akhter, T. E. Mallouk, J. Phys. Chem. 92, 2597 (1988).

16. G. Cao, H.-G. Hong, T. E. Mallouk, Acc. Chem. Res. 25, 420 (1992)

17. S. F. Bent, M. L. Schilling, W. L. Wilson, H. E. Katz, A. L. Harris, Chem. Mater. 6, 122 (1994).

18. S. T. Wilson, B. M. Lok, C. A Messina, T. R. Cannan, E. M. Flanigen, in Intrazeolite Chemistry, G. D. Stucky et al., Eds. (ACS Symp. Ser. 218, American Chemical Society, Washington, DC, 1989), p. 79.

19. U. Müller and K. K. Unger, Z. Kristallogr. 182, 190 (1988); S. Quu, W. Pang, H. Kessler, J.-L. Guth, Zeolites 9, 440 (1989).

20. J. Kornatowski and G. Finger, Bull. Soc. Chim. Belg. 99, 857 (1990)

21. This research was supported by the National Science Foundation and the Purdue Research Foundation.

24 May 1994; accepted 3 August 1994

\title{
Greenland Ice Evidence of Hemispheric Lead Pollution Two Millennia Ago by Greek and Roman Civilizations
}

\author{
Sungmin Hong, Jean-Pierre Candelone, Clair C. Patterson, \\ Claude F. Boutron*
}

Analysis of the Greenland ice core covering the period from 3000 to 500 years agothe Greek, Roman, Medieval and Renaissance times-shows that lead is present at concentrations four times as great as natural values from about 2500 to 1700 years ago (500 B.C. to 300 A.D.). These results show that Greek and Roman lead and silver mining and smelting activities polluted the middle troposphere of the Northern Hemisphere on a hemispheric scale two millennia ago, long before the Industrial Revolution. Cumulative lead fallout to the Greenland Ice Sheet during these eight centuries was as high as 15 percent of that caused by the massive use of lead alkyl additives in gasoline since the 1930s. Pronounced lead pollution is also observed during Medieval and Renaissance times.

The history of human lead production began about six millennia ago (Fig. 1A) (17). Significant lead production started only

S. Hong and J.-P. Candelone, Laboratoire de Glaciologie et Géophysique de l'Environnement du CNRS, 54 rue Molière, Domaine Universitaire, B.P. 96, 38402 Grenoble/Saint Martin d'Hères, France.

C. C. Patterson, Division of Geological and Planetary Sciences 170-25, California Institute of Technology, Pasadena, CA 91125, USA.

C. F. Boutron, Laboratoire de Glaciologie et Géophysique de l'Environnement du CNRS, 54 rue Molière, Domaine Universitaire, B.P. 96, 38402 Grenoble/Saint Martin d'Héres, and UFR de Mécanique, Université Joseph Fourier de Grenoble, Domaine Universitaire, B.P. 68, 38041 Grenoble, France.

*To whom correspondence should be addressed. about one millennium later with the discovery of new techniques for smelting leadsilver alloys from lead sulfide ores (galena) and cupeling silver from the alloys (1-7). Lead production then rose continuously during the Copper, Bronze, and Iron ages $(5,6,8)$, stimulated by the introduction of silver coinage (during those times, lead was as much as a 300-to-1 by-product of silver production) and the development of Greek civilization. A pronounced maximum of about 80,000 metric tons per year (approximately the rate at the time of the Industrial Revolution) was reached during the flourishing of Roman power and influence around two millennia ago (Fig. 1A). The use of lead was ubiquitous, and most districts that were suitable for mining in the Old World were known and worked, especially those in Spain, the Balkans, Greece, and Asia Minor $(5,7)$. Lead production then decreased sharply during the decline of the Roman Empire, down to a minimum of only a few thousand tons per year during medieval times, before increasing again from A.D. 1000 with the discovery of the lead and silver mines of Central Europe.

Lead poisoning from extensive lead production and use during Roman times has been suggested as one of the causes of the fall of Rome $(5,9,10)$. Smelter emissions from these sources have also been documented as resulting in significant local or even regional lead pollution in Europe, as evidenced, for instance, by studies of peat deposits in Britain $(11,12)$ and lake sediments in southern Sweden (13). We show here that smelter emissions also resulted in significant contamination of the middle troposphere of the remote Arctic. This occurrence marks the oldest large-scale hemispheric pollution ever reported, long before the onset of the Industrial Revolution.

We analyzed 22 sections of the 3028.8-m European Greenland Ice-Core Project (GRIP) deep ice core electromechanically drilled in 1990 to 1992 at Summit $\left(72^{\circ} 34^{\prime} \mathrm{N}, 37^{\circ} 37^{\prime} \mathrm{W}\right.$, elevation of $3238 \mathrm{~m}$ above sea level, annual mean air temperature of $-32^{\circ} \mathrm{C}$ ) in central Greenland (14). Fourteen sections were selected from the period between 2360 and 1775 years ago (depths of 511.0 to $349.3 \mathrm{~m}$ ), which are the $\sim 600$ years corresponding to the flourishing of the Roman Republic and Empire. Two sections were selected from ice deposited 3000 to 2500 years ago (depths of 619.3 to $569.3 \mathrm{~m}$, respectively), a period that includes the rise of Greek civilization. Five sections were selected from ice deposited 1520 to 470 years ago (depths of 349.3 to $129.3 \mathrm{~m}$, respectively), during the Medieval and Renaissance periods. Finally, one section was chosen in ice from the pre-lead production period ( 7760 years ago, depth of $1286.5 \mathrm{~m}$ ) to serve as a Holocene natural background sample. It was not possible to analyze samples deposited 3500 to 7000 years ago because this period corresponds to the brittle-zone depth interval in which the core quality is too poor to allow reliable measurements of heavy metals.

We mechanically decontaminated each core section (length of $55 \mathrm{~cm}$ ) using an ultraclean procedure (17) derived from those of Patterson and his co-workers (15, 16). It involved the chiseling of successive veneers of ice from the outside to the central part of each section inside a laminarflow clean bench in a cold room while the core was held horizontally in an all-polyeth- 